University of Nebraska - Lincoln

DigitalCommons@University of Nebraska - Lincoln

2018

\title{
Investigation of toppling ball flight in American football with a mechanical field-goal kicker
}

\author{
Chase M Pfeifer \\ University of Nebraska - Lincoln, cpfeifer@madonna.org \\ Timothy J. Gay \\ University of Nebraska - Lincoln, tgay1@unl.edu \\ Jeff A. Hawks \\ University of Nebraska-Lincoln, jhawks2@unl.edu \\ Shane Farritor \\ University of Nebraska - Lincoln, sfarritor@unl.edu \\ Judith M. Burnfield \\ Madonna Rehabilitation Hospital, jburnfield@madonna.org
}

Follow this and additional works at: https://digitalcommons.unl.edu/mechengfacpub

Part of the Engineering Physics Commons, Other Applied Mathematics Commons, Other Engineering Science and Materials Commons, and the Other Mechanical Engineering Commons

Pfeifer, Chase M; Gay, Timothy J.; Hawks, Jeff A.; Farritor, Shane; and Burnfield, Judith M., "Investigation of toppling ball flight in American football with a mechanical field-goal kicker" (2018). Mechanical \& Materials Engineering Faculty Publications. 598.

https://digitalcommons.unl.edu/mechengfacpub/598

This Article is brought to you for free and open access by the Mechanical \& Materials Engineering, Department of at DigitalCommons@University of Nebraska - Lincoln. It has been accepted for inclusion in Mechanical \& Materials Engineering Faculty Publications by an authorized administrator of DigitalCommons@University of Nebraska Lincoln. 


\title{
Investigation of toppling ball flight in American football with a mechanical field-goal kicker
}

\author{
Chase M. Pfeifer, ${ }^{1}$ Timothy J. Gay, ${ }^{2}$ Jeff A. Hawks, ${ }^{3}$ \\ Shane M. Farritor, ${ }^{3}$ \& Judith M. Burnfield ${ }^{1}$
}

\author{
1 Institute for Rehabilitation Science and Engineering, Madonna Rehabilitation \\ Hospital, 5401, South St., Lincoln, NE 68506, USA \\ 2 Department of Physics \& Astronomy, University of Nebraska-Lincoln, \\ 073 Jorgensen Hall, Lincoln, NE 68588, USA \\ 3 Department of Mechanical and Materials Engineering, University of \\ Nebraska-Lincoln, W358 NH, Lincoln, NE 68506, USA \\ Correspondence — Chase M. Pfeifer, cpfeifer@madonna.org
}

\begin{abstract}
A mechanical field-goal kicking machine was used to investigate toppling ball flight in American football place-kicking, eliminating a number of uncontrollable impact variables present with a human kicker. Ball flight trajectories were recorded using a triangulation-based projectile tracking system to account for the football's 3-dimensional position during flight as well as initial launch conditions. The football flights
\end{abstract}

Published in Sports Engineering 21 (2018), pp 95-102

doi:10.1007/s12283-017-0254-x

Copyright (c) 2017 International Sports Engineering Association 2017; published by Springer. Used by permission.

Suggested citation: Pfeifer, C.M., Gay, T.J., Hawks, J.A. et al. Investigation of toppling ball flight in American football with a mechanical field-goal kicker. Sports Eng 21, 95-102 (2018). https://doi.org/10.1007/s12283-017-0254-x 
were described using kinematic equations relating to projectile motion including stagnant air drag and were compared to measured trajectories as well as projectile motion equations that exclude stagnant air drag. Measured football flight range deviations from the non-drag equations of projectile motion corresponded to deficits between 9 and 31\%, which is described by a football toppling compound drag coefficient of $0.007 \pm 0.003 \mathrm{~kg} / \mathrm{m}$. Independent variables including impact location and impact angle orientation resulted in 15 impact conditions. We found that an impact location of $5.5 \mathrm{~cm}$ from the bottom of the ball maximized trajectory height and distance. At the $5.5-\mathrm{cm}$ impact location, alterations in impact angle produced minimal change in football trajectory, including launch angle (range $=1.96 \mathrm{deg}$ ), launch speed $($ range $=1.06 \mathrm{~m} / \mathrm{s})$, and range $($ range $=0.94 \mathrm{~m})$.

Keywords: Kicking, Football, Drag, Place-kicking, American football, Trajectory

\section{Introduction}

Projectiles from many sports have prompted robust aerodynamic studies both experimentally and through simulations [1]. Toppling (end-over-end) ball flight in American football is an important aspect of the game that is commonly overshadowed by spiraling ball flight. Many studies have investigated aerodynamic factors for flight when the ball's velocity vector and long axis are roughly parallel, both with and without rotation [1-5]. Investigation of toppling flight, which is typical of kicked footballs, can be more complicated due to the rapidly changing angle between the ball's long axis and its direction of motion [6]. Researchers have used game data from the National Football League (NFL) to analyze launch angles, hang-times, and distances for kick-offs, punts, and field-goals using aerodynamics and projectile motion $[6,7]$. Aerodynamic factors experienced by the football through toppling flight have been investigated through computer simulations [8].

While results from these football studies suggest knowledge of initial conditions (e.g., launch angle and speed) can be used to predict kick distance and hang-time, little research has been performed to determine the ideal conditions for striking the football to create these initial conditions. In part, variability in human performance across kicks and between kickers makes it difficult to control for the influence of factors such as impact location and impact angle on flight trajectory. Equations for predicting projectile motion [9] 
coupled with research performed by Brancazio et al. (1985) suggest that a launch angle of $\sim 45^{\circ}$ would be ideal for maximum horizontal ball flight regardless of speed.

To eliminate the influence of human variability on flight trajectory, this study used a mechanical field-goal kicking machine to investigate the relationship between impact location and angle on resulting football trajectories. We hypothesized that a launch angle of $\sim 45^{\circ}$ would result in the longest ball flight, and that a limited combination of impact angles and locations would contribute to the desired launch angle.

\section{Methods}

\subsection{Instrumentation}

A pendulum-based mechanical kicking machine driven by a winch and compression spring was used to strike a football [10] (Figure 1). The device consisted of a cylindrical impactor $(13 \mathrm{~cm}$ in diameter) and an adjustable tee that was used to orient the ball for impact at the desired height and angle (Figure 2). The winch attached to a pulley that was rigidly connected to the impactor by a $68.6 \mathrm{~cm}$ aluminum I-beam.

(A) Pre-Loading

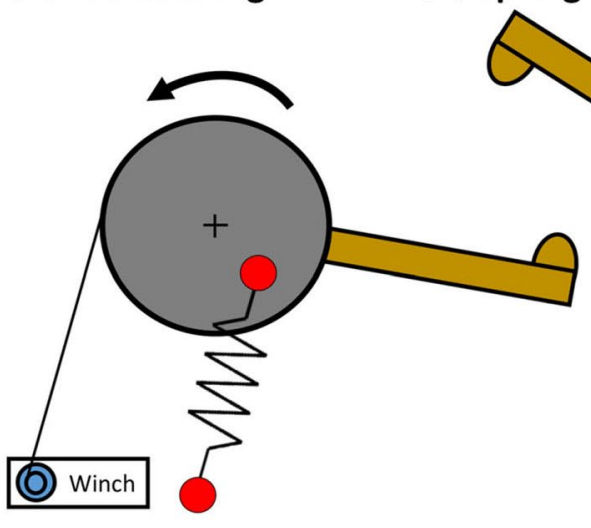

(B) Spring Reaching Fulcrum

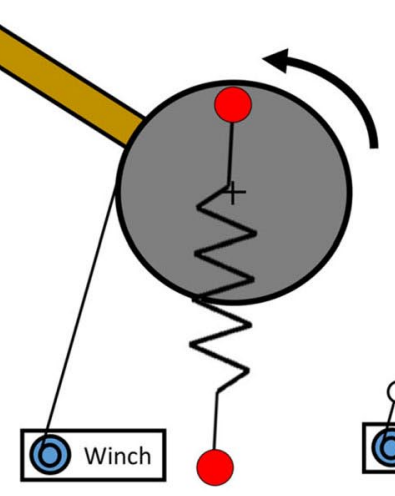

(C) Impactor Swinging Through

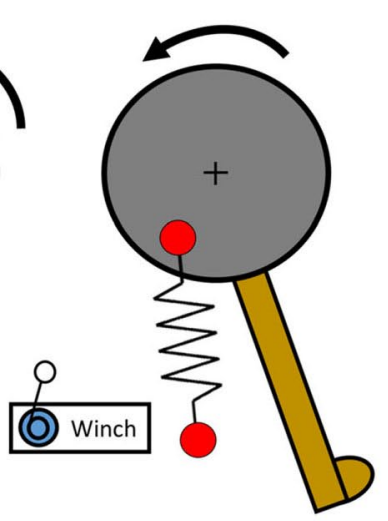

Figure 1 Mechanical field-goal kicker schematic, illustrating winch and spring concept. 


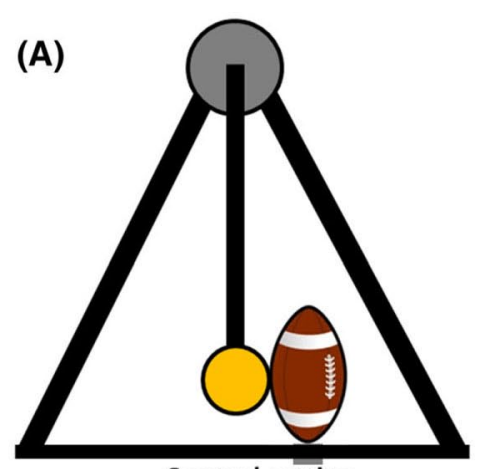

Control setting

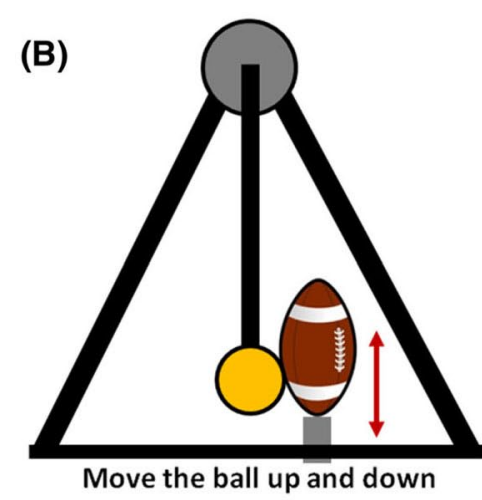

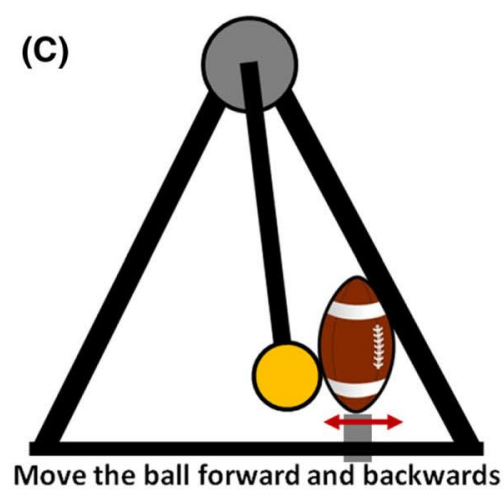

Figure 2 Mechanical kicker and football configurations: a) baseline; b) adjusting impact location along long axis of ball; $\mathbf{c}$ ) adjusting directional component of impact force.

When the winch was activated it rotated the pulley, loading the compression spring until the spring/pulley contact location overcame the fulcrum of the system causing the spring to take over, swinging the impactor through contact with the football.

Impact speed was controlled by the specifications of the winch and compression spring. A Qualisys motion tracking system (Qualisys, Göteborg, Sweden) was used to determine the movement of the impactor through the swing cycle. In particular, a reflective marker, placed on the impact location of the impactor, provided three-dimensional kinematics of the impactor through its pre-contact swing cycle. The kinematics of one such swing cycle is presented in Figure 3, where both the speed and vertical position of the impactor are graphed through a swing. Ten repetitions were recorded and determined that the mean impact speed was $11.57 \pm 0.03 \mathrm{~m} / \mathrm{s}$.

A standard regulation National Collegiate Athletic Association football was used; it was $29.2 \mathrm{~cm}$ long, weighed $0.411 \mathrm{~kg}$, and was inflated to $89.6 \mathrm{kPa}$. Its circumference was roughly $71 \mathrm{~cm}$ along the long axis of the ball and $53 \mathrm{~cm}$ on the short axis. Air pressure was checked every 5 kicks to ensure a constant inflation.

To quantify the flight trajectory, a projectile tracking system was used to determine the three-dimensional (3D) location of the ball from launch to landing [11]. This system uses multiple camera views to triangulate the location of a projectile in 3D space and was found to deviate from a Qualisys infrared tracking system by less than $5 \%$ with respect to horizontal distance traveled by the object. 


\section{Mechanical Kicker: Impactor Dynamics}

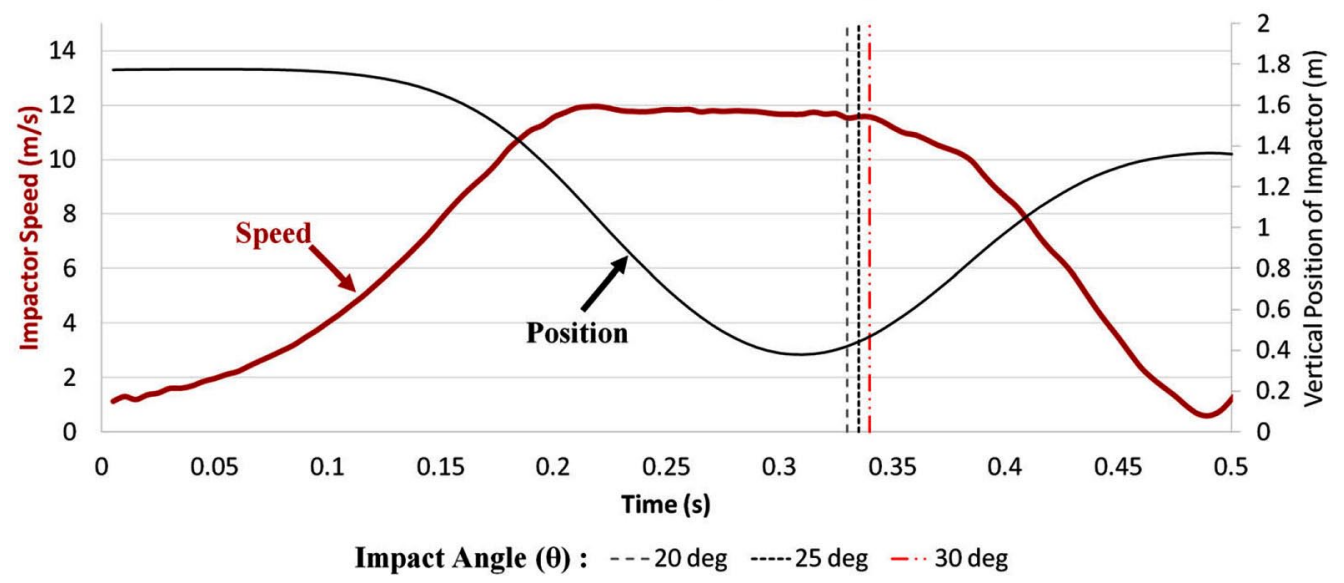

Figure 3 Mechanical kicker impactor kinematics, showing the impactor position and speed through a single swing, initiated at $t=0 \mathrm{~s}$ [10]. Vertical dashed lines indicate when the impactor contacts the ball for independent variable $\theta$, the impactor strike angle (see also Figure 4).

\subsection{Procedures}

To reduce the influence of changing atmospheric variables on ball flight (e.g., wind speed and direction), all testing took place on an indoor football field (University of Nebraska's Hawks Champion Center). The average temperature, humidity, and atmospheric pressure were $24 \pm 2{ }^{\circ} \mathrm{C}, 85 \pm 4 \% \mathrm{rH}$, and $99.7 \pm 0.1 \mathrm{kPa}$, respectively.

A total of 15 different impact conditions were investigated including five impact locations and three impact angles. Specifically, impact locations [referenced to the bottom of the ball $(\beta)$ ], were $13 \mathrm{~cm}$ (just below center), 10.5, 8, 5.5 and 3 (see Figure 4). At each of these impact locations, the football was manipulated so that the impactor struck the ball at an angle $\theta$ of $20^{\circ}, 25^{\circ}$, or $30^{\circ}$. As shown in Figure 4, $b$ (impact parameter) is the lever arm of the force the impactor applies to the ball; a positive value tends to make the ball rotate counterclockwise and a negative value induces clockwise tumbling. Three impacts/launches for each $(\beta, \theta)$ pair were recorded, resulting in a total of 45 trials. 


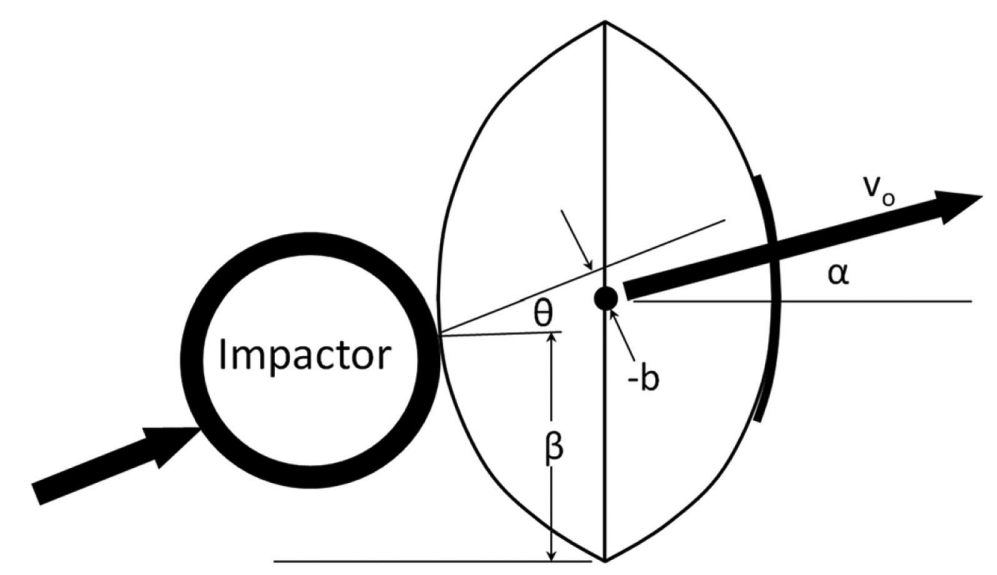

Figure 4 Definition of impact and launch variables.

\subsection{Data analysis}

Projectile motion can be described for the case of no air drag [12]. We assume that the ball is launched in the $x-y$ plane at ground $(y=$ 0 ) level and at $x=0$ with an initial speed $v_{0}$ at an angle $\alpha$ above the horizontal (Figure 4). It will return to earth a horizontal distance $R$ (the "range") from its launch point after having been in flight for time $T$ (the "hang-time") so that

$$
\begin{gathered}
y(x)=\tan (\alpha) x-\frac{g x^{2}}{2\left(v_{0} \cos (\alpha)\right)^{2}} \\
R=\frac{v_{0}^{2} \sin (2 \alpha)}{g}
\end{gathered}
$$

and

$$
T=\frac{2 v_{0} \sin (\alpha)}{g}
$$

where $g$ is the acceleration due to gravity. The ball's initial speed, $v_{0^{\prime}}$ and toppling rotational velocity, $\omega$, are determined to a good approximation by the force of the impact, $F_{1}$ its duration, $\Delta t$, the angle at which it is directed, $\theta$, and the location of its application, $\beta$ (Figure 4). Thus,

$$
F_{l} \Delta t=m v_{0}
$$


and

$$
F, b \Delta t=I_{z} \omega
$$

where $I_{z}$ is the moment of inertia of the ball about its semiminor axis. One can then show that

$$
\omega=m v_{0} b / I_{z}
$$

When air drag becomes important, we can characterize the total force on the ball in flight as [4]

$$
\vec{F}=-m g \hat{y}-1 / 2 \rho v^{2} S C_{D} \hat{v}
$$

where $m$ is the ball's mass, the first term on the right-hand side is the force due to gravity, the second term is the drag force antiparallel to the ball's velocity vector, $\rho$ is the air density, $v$ is the ball's speed, $S$ is the ball's "reference area" that is independent of the ball's pitch angle, and $C_{D}$ is the coefficient of drag that depends on the ball's pitch. Equation 7 was used to computationally assess the importance of air drag on the ball's trajectory.

\subsection{Statistical analysis}

To determine the influence of impact location on distance traveled, regression analysis (either linear or polynomial depending on the relationship) with repeated measures for impact location, $\beta$, were performed to determine a relationship between $\beta$ and $\alpha, v_{0}, R$, maximum ball height $\left(y_{\max }\right)$, and $T$. The same analyses were performed with respect to the independent variable $\theta$ to examine the influence of impact angle on these same outcome variables. Comparison of the compound drag coefficient, $C_{C D}=1 / 2 \rho S C_{D^{\prime}}$ (explained below) and $\beta$ were made through a linear regression.

\section{Results}

Three trajectories were recorded and averaged for each impact condition. Uncertainties are taken to be the standard deviation of the three measurements. Trajectories $(y(x)), R, T, \alpha$, and $v_{0}$, were examined as a function of $\beta$ and $\theta$. Statistical analysis (Table 1) showed that impact location played a larger role on outcome measures than impact angle. 
Table 1 Multiple regression analysis comparing independent variables and outcome measures ( $P \leq 0.05$ denotes statistical significance)

\begin{tabular}{lll} 
& $\beta$ & $\theta$ \\
\hline$\alpha$ & $P=<0.001$ & $P=0.680$ \\
$v_{0}$ & $P=0.040$ & $P=0.295$ \\
$R$ & $P=<0.001$ & $P=0.885$ \\
$y_{\max }$ & $P=<0.001$ & $P=0.818$ \\
$T$ & $P=<0.001$ & $P=0.948$ \\
\hline
\end{tabular}

These correlations are displayed in Figure 5, where the relationship between the independent variable $\beta$ and the outcome measures is shown.

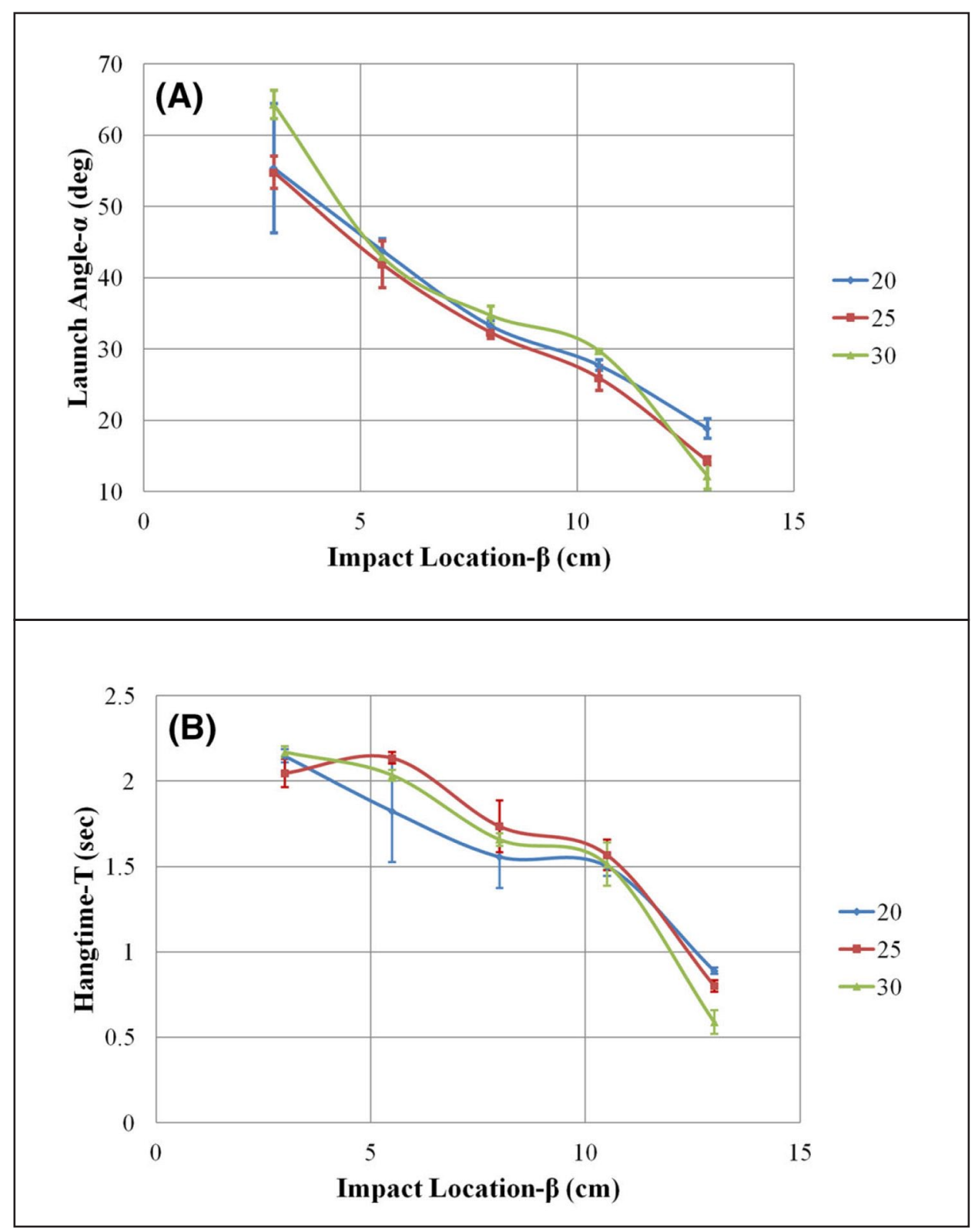




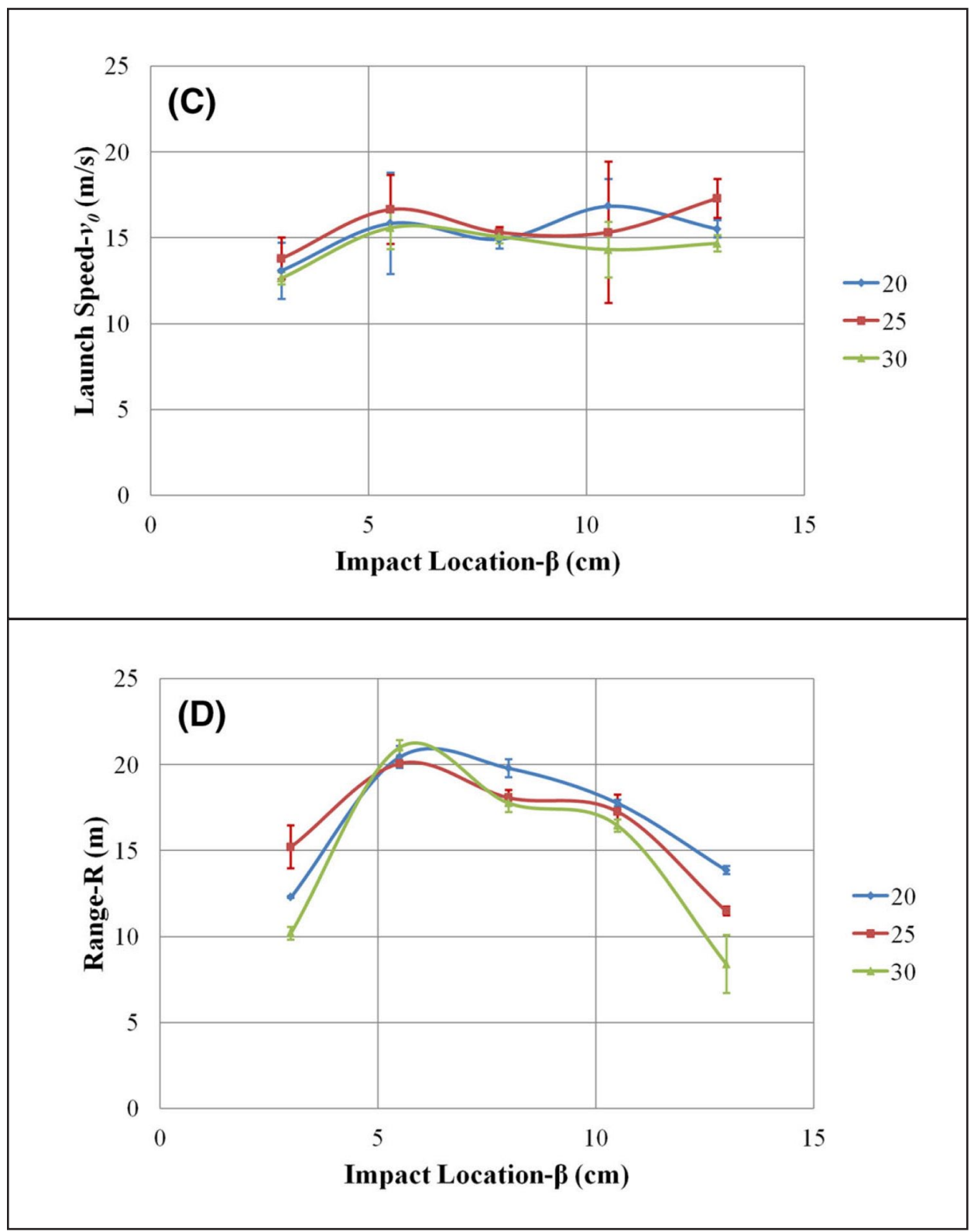

Figure 5 Impact location's influence on outcome measures; vertical error bars represent a single standard deviation of the ordinate values for each condition. 
Knowing the outcome measures $\left(v_{0}\right.$ and $\left.\alpha\right)$, a projected distance for each trial (neglecting air resistance) was calculated using Eq. 2. In all cases, projected distances proved to be larger than measured distances with differences ranging between 19 and $31 \%$. Greater differences generally occurred when the ball traveled further distances. Figure 6 depicts average trajectories for impacts at the $5.5 \mathrm{~cm}$ location.
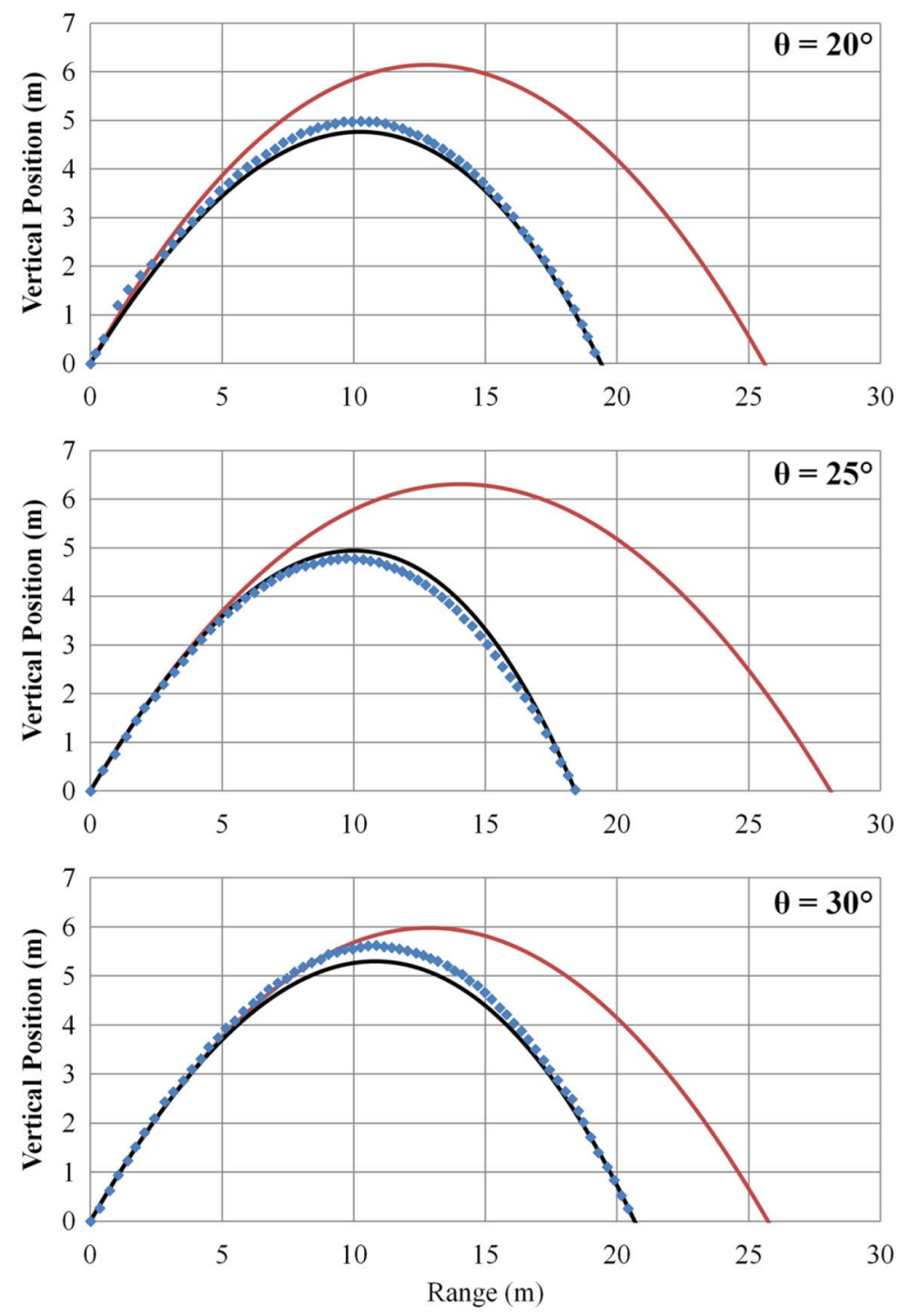

- Measured —No Drag —Drag

Figure 6 Average projected trajectory versus average measured trajectory example $(\beta=5.5 \mathrm{~cm})$. Each measured trajectory is the average of three trials. The "Drag" and "No Drag" curves illustrate projected trajectories with and without applying drag to the system while using the average initial launch conditions from measured trials. 


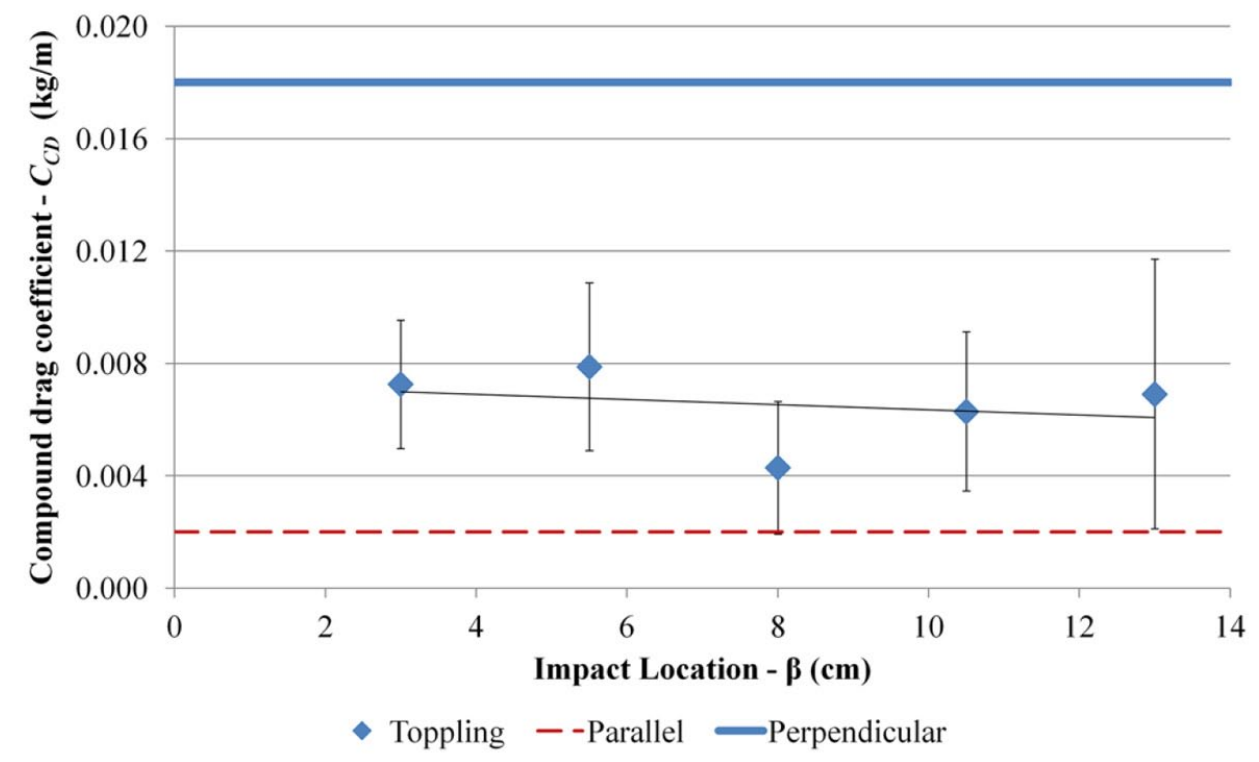

Figure 7 Effect of impact location on football compound drag coefficient, $C_{C D}$ (mean and one standard deviation). "Parallel" and "Perpendicular" lines indicate drag coefficients determined by Rae and Streit (2002) [3] for air flow parallel and perpendicular to the football's long axis.

By integrating Eq. 7 using $1 \mathrm{~ms}$ time increments, we calculated an effective drag coefficient, $C_{D^{\prime}}$ averaged over all pitch angles of the ball during its flight. The individual launch conditions $v_{0}$ and $\alpha$ were used in the integration, and the compound drag coefficient was varied as a single parameter until the computed range $R$ matched the measured one. Using Rae and Streit's values for $S\left(0.0233 \mathrm{~m}^{2}\right)$ and $\rho$ $\left(1.226 \mathrm{~kg} / \mathrm{m}^{3}\right)$ [3], we determined the $C_{\mathrm{CD}}$ as a function of the impact angle $\theta$ and location $\beta$; these results are shown in Figure 7. A linear regression was performed resulting in an $R^{2}$ value of 0.122 , suggesting that under our experimental conditions the compound drag coefficient for a toppling football is independent of kick impact location, and has an average value of $0.007 \pm 0.003 \mathrm{~kg} / \mathrm{m}$. This is in good agreement with the equivalent values measured by Rae and Streit in a wind tunnel experiment for the ball axis perpendicular and parallel to the wind flow $(0.018 \mathrm{~kg} / \mathrm{m}$ and $0.002 \mathrm{~kg} / \mathrm{m}$, respectively, which were confirmed by Alam et al. [13]), and shows that the effective toppling drag force lies between that for the cases where the ball's axis lies parallel and perpendicular to the wind flow. We note in this regard that Rae and Streit measured drag force for a ball spinning about its long axis, and that the drag coefficient was essentially the same for both spin rates of 600 and $100 \mathrm{rpm}$. 


\section{Discussion}

The nature of toppling football flight makes it challenging to model, replicate, and track. There are thus few studies that investigate this topic. The intent of this study was to introduce a methodology for examining physical toppling football flight and investigate how the main input variables of place-kicking (impact location and angle) effect flight trajectory.

The data demonstrate that the impact location, $\beta$, strongly influences the outcome measures whereas the impact angle, $\theta$, had less effect. It was observed that an impact at the $5.5 \mathrm{~cm}$ location consistently sent the ball higher and farther than the other conditions, independent of the angle of impact. Further investigation of the relationship between impact location and launch angle showed a distinctly quasi-linear relationship. Figure 5 a clearly indicates that the lower the impact on the ball, the larger the launch angle, corresponding to the enhanced "loft" of the impact for these locations. Given the relationship seen in Figure $5 \mathrm{a}$, the dependence of $T$ and $R$ on $\beta$ (Figure $5 \mathrm{~b}, \mathrm{~d}$ ) follows directly. As $\alpha$ drops from $60^{\circ}$ to $15^{\circ}$ with increasing $\beta$, we pass through a maximum $R$ at $\alpha \approx 45^{\circ}$, as expected, and the hang-time falls with launch angle as well. This is predicted directly by the kinematic relationships of Eqs. 2 and 3.

Equation 1 tells us that the ideal launch angle for maximum distance in the absence of air drag is $45^{\circ}$. For a given range, this corresponds to the smallest possible launch speed of the ball. Similar results were obtained in this work as impact at the $5.5 \mathrm{~cm}$ location resulted in the furthest horizontal distances $(20.5 \pm 0.5 \mathrm{~m})$ corresponding to an average launch angle of $43^{\circ} \pm 1^{\circ}$ (see Figure 8). This agrees with Brancazio's findings that a launch angle between $40^{\circ}$ and $45^{\circ}$ would be optimal for maximum horizontal distance [6]. Using numerical simulations that included the effects of drag, Gay showed that for a spiral pass the best launch angle for maximum range was about $43^{\circ}$ [7]. For a toppling end-over-end kick, however, Gay's simulations indicated an optimal angle of $38^{\circ}$ [7]. This is consistent with our results shown in Figure 8, given that one of the experimental error bars in the maximum-range group reaches a lower limit of about $38^{\circ}$. Another possibility is that there is some weak negative lift associated with our launch conditions, reducing the "effective" launch angle a bit from the actual $43^{\circ}$ to a more optimal value. 

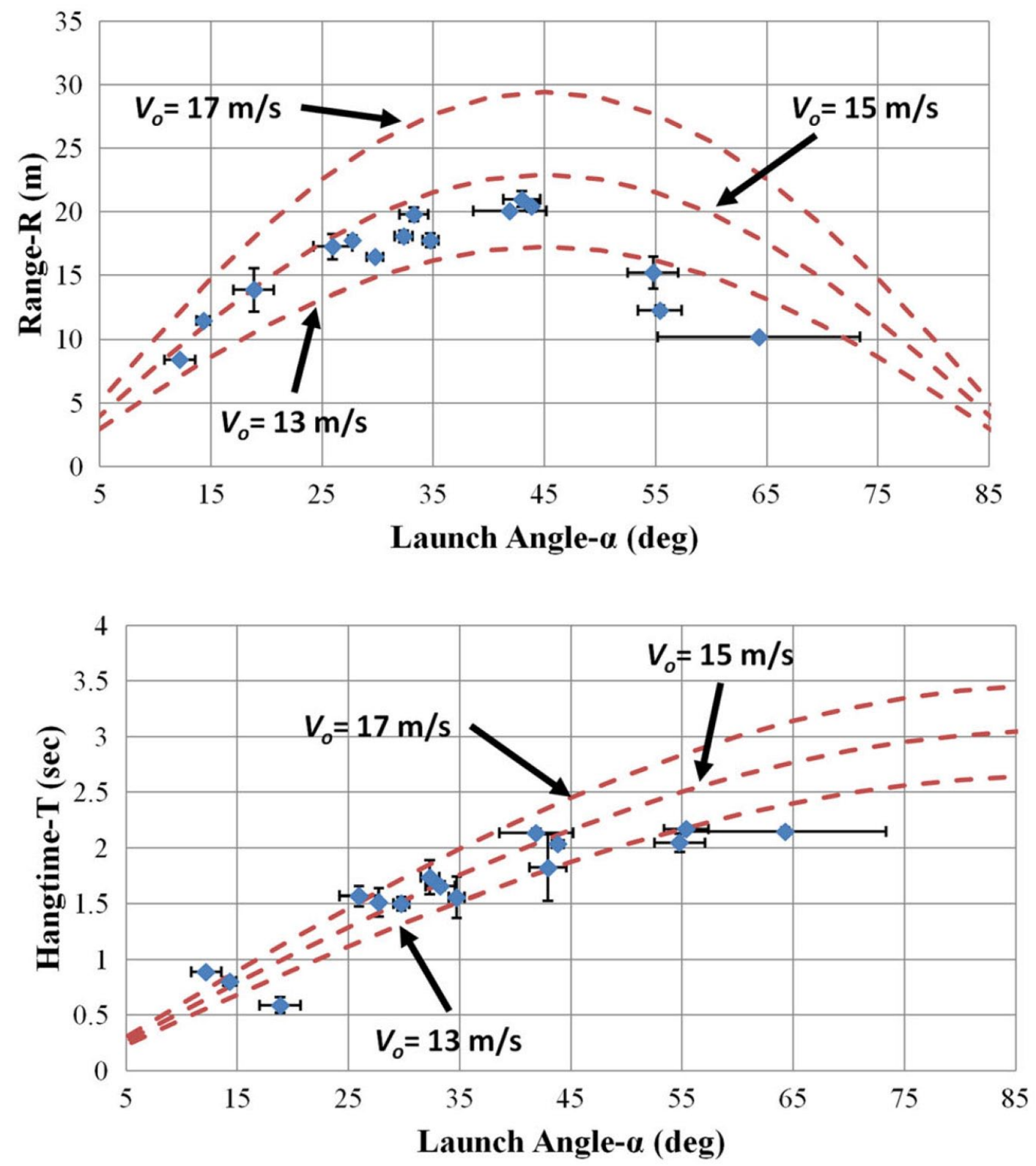

Figure 8 Relationship between launch angle $(\alpha)$ and range. Projected curve portrays Eq. 2 where $v_{0}$ is equal to 12,14 , or $16 \mathrm{~m} / \mathrm{s}$ to illustrate the range observed in this study.

As can be observed from Figure 5, at the more extreme impact locations ( 13 and $3 \mathrm{~cm}$ ) the angle of impact noticeably influenced both launch angle and range. This was less evident over the middle three impact locations $(10.5,8$, and 5.5$)$. 
Examination of launch speed, $v_{0}$ (Figure $5 c$ ), showed relatively constant results throughout kick variations (i.e., impact location and impact angle) although the $v_{0} \mathrm{~s}$ for the $\beta=3 \mathrm{~cm}$ condition were systematically low (average $13.2 \pm 0.5 \mathrm{~m} / \mathrm{s}$ ). For $\beta=5.5 \mathrm{~cm}$, the average launch speed was $0.9 \mathrm{~m} / \mathrm{s}(6 \%)$ higher than the overall average, suggesting that the location of impact along the long axis of the football does affect launch speed.

Figure 8 illustrates how our measured trajectories follow Eqs. 2 and 3. The fact that launch speed, $v_{0^{\prime}}$ varies little with impact location or angle, with the exception of the lowest impacts at $\beta=3 \mathrm{~cm}$ (Figure $5 c)$, means that we can isolate the dependence of range, $R$, and hangtime, $T$, on the launch angle, $\alpha$, alone. The values for these quantities, assuming no air drag, are shown for launch speeds of 13,15 and $17 \mathrm{~m} / \mathrm{s}$. Thus, in the absence of drag, one would expect our $\beta=3 \mathrm{~cm}$ experimental data (the right-hand three data points on the graphs) to cluster around the $13 \mathrm{~m} / \mathrm{s}$ theory curve, given that their average launch speed is $13.2 \pm 0.5 \mathrm{~m} / \mathrm{s}$. Similarly, the rest of the data is tightly distributed around an average launch speed of $15.1 \pm 0.6 \mathrm{~m} / \mathrm{s}$, and it would cluster near the $15 \mathrm{~m} / \mathrm{s}$ theory curve. The fact that these data fall generally below their respective no-drag theory curves is due to the air-drag force term on the right-hand side of Eq. 7 .

In examining the compound drag coefficient, little correlation was found when compared to the independent variables or outcome measures. Our initial assumption was that CCD would vary with the angular velocity of the ball about its axis of symmetry parallel to the earth's surface. Such observations were made by Asai, Kobayashi, and Sakashita when examining a rotating soccer ball [14] as well as Bearman and Harvey when investigating a rotating golf ball [15]. Therefore, we were surprised by the lack of dependence of $C_{C D}$ on $\beta$, shown in Figure 7. Studies such as those by Rae and Streit [3] and Djamovski et al. [16] investigated aerodynamic drag associated with different pitch angles of an American football and a rugby ball, respectively, but they did not examine the aerodynamic drag associated with toppling rotation of a non-spherical ball.

We can develop an elementary understanding of our result by considering the angular velocity, $\omega$, of the ball that is produced as a result of its launch conditions. As discussed above, the values of $\theta$ and $\beta$ establish the impact parameter that determined both the angular speed and direction of the ball's toppling motion. Knowing how 
the hang-time depends on $\theta$ and $\beta$ allows us to determine the total number of toppling rotations a ball executes during its flight; this is shown in Figure 9. The largest toppling rotation rates occur for $[\theta, \beta]$ $=\left[30^{\circ}, 13 \mathrm{~cm}\right]$, corresponding to $\mathrm{a} b=-3.2 \mathrm{~cm}$ and a clockwise $\omega$ of
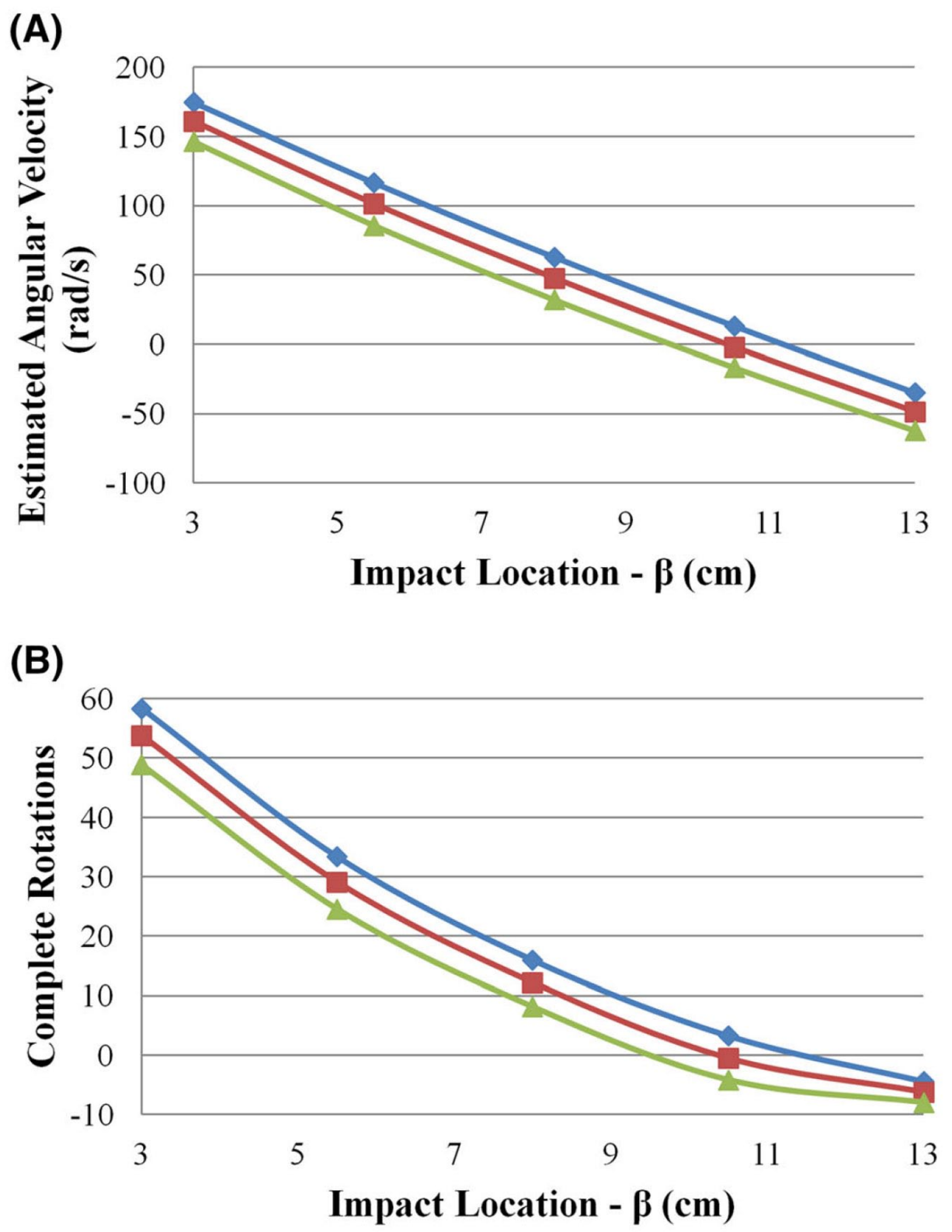

Figure 9 Estimated angular velocity (a) and number of toppling rotations (b) executed by a ball when the impact angle and location are varied. A positive angular velocity/number of rotations correspond to anti-clockwise rotation (top of the ball moving backward towards the launch point); negative angular velocity/ rotation numbers correspond to clockwise rotation. 
$62 \mathrm{rad} / \mathrm{s}$ (per the frame of reference indicated in Figure 4), and $[\theta, \beta]$ $=\left[20^{\circ}, 3 \mathrm{~cm}\right]$, corresponding to $\mathrm{a} b=9.1 \mathrm{~cm}$ and an anti-clockwise $\omega$ of $175 \mathrm{rad} / \mathrm{s}$. Even in the slowest rotation case, in which $[\theta, \beta]=$ $\left[25^{\circ}, 10.5 \mathrm{~cm}\right]$, corresponding to $\mathrm{a} b=-0.1 \mathrm{~cm}$ and a clockwise $\omega$ of $2 \mathrm{rad} / \mathrm{s}$, the ball attains all possible pitch angles during its $1.5 \mathrm{~s}$ flight. Thus we argue that the ball is sufficiently rotating rapid enough for all launch conditions so that the compound drag coefficient (Figure 7) effectively averages to a value between the cases corresponding to pitch angles of $0^{\circ}$ and $90^{\circ}$.

\section{Conclusions}

A mechanical field-goal kicking machine was designed and used to investigate American football place-kicking, eliminating the human kicking component to allow for controlled impact variables. Quantification of the trajectories was performed using a projectile tracking system to determine the football's 3D position through flight as well as its initial launch conditions.

Our findings suggest that the football trajectory is well described by the basic kinematic equation describing projectile motion when stagnant air drag proportional to the square of the ball's speed is included. Measured drag coefficients of $0.007 \pm 0.003 \mathrm{~kg} / \mathrm{m}$ resulted in trajectory deviation from the projected equation of projectile motion by $9-31 \%$, with greater differences generally observed when the ball traveled further distances.

It was found that an impact location of $5.5 \mathrm{~cm}$ from the bottom of the ball resulted in the best trajectories with regard to height, distance, and consistency $\left(R=20.5 \pm 0.5 \mathrm{~m}, \alpha=42.9^{\circ} \pm 1.0^{\circ}, v_{0}=16.0 \pm\right.$ $0.6 \mathrm{~m} / \mathrm{s}$ ). At this impact location, alterations in impact angle had limited effect on football trajectory, launch angle, launch speed, and horizontal distance traveled.

These results suggest that impact location is more influential than impact angle. Striking the ball $5.5 \mathrm{~cm}$ above the ground (roughly $1 / 5$ th of the ball height) results in launch angles around $40^{\circ}-45^{\circ}$ which correlate to the ball traveling further. Impacts lower on the ball (i.e., $3 \mathrm{~cm}$ from the ground) yield larger launch angles $\left(\alpha=58.1^{\circ} \pm 5.3^{\circ}\right)$ and reduced range $(R=12.6 \pm 2.5 \mathrm{~m})$. 
Acknowledgments This research greatly benefited from the help of our research assistants, Andrew Palmesano, Margret Clay, and Jesse Lin. We would also like to acknowledge the Nebraska Athletic Performance Lab and the Athletics Department at the University of Nebraska-Lincoln for providing the laboratory space necessary for performing this study. This work was supported in part by the National Science Foundation through award PHY-1505794(TJG).

Conflict of interest The authors have no conflict of interest.

\section{References}

1. Goff JE (2013) A review of recent research into aerodynamics of sport projectiles. Sports Eng 16(3):137-154

2. Watts RG, Moore G (2003) The drag force on an American football. Am J Phy 71(8):791-793

3. Rae WJ, Streit RJ (2002) Wind-tunnel measurements of the aerodynamic loads on an American football. Sports Eng 5(3):165-172

4. Rae WJ (2003) Flight dynamics of an American football in a forward pass. Sports Eng 6(3):149-163

5. Cunningham J, Dowell L (1976) The effect of air resistance on three types of football trajectories. Res Quarterly Am Alliance Health Phys Educ Recreat 47(4):852-854

6. Brancazio PJ (1985) The physics of kicking a football. Phys Teach 23(7):403-407

7. Gay T (2004) Football physics: the science of the game. Rodale, Harlan, pp 129-165

8. Lee WM, Mazzoleni AP, Zikry MA (2013) Aerodynamic effects on the accuracy of an end-over-end kick of an American football. Sports Eng 16(2):99-113

9. Tipler PA, Mosca G (2007) Physics for scientists and engineers. Macmillan, Basingstoke

10. Pfeifer CM (2015) Biomechanical investigation of elite placekicking. Dissertation, University of Nebraska-Lincoln

11. Pfeifer CM, Burnfield JM, Twedt MH, Cesar GM, Hawks JA (2016) Video capture and post processing technique for approximating 3D projectile trajectory. Sports Tech. doi:10.1080/19346182.2016.1248974

12. Rouse H (2011) Dover books on physics: elementary mechanics of fluids. Dover, Mineola, New York

13. Alam F, Smith S, Chowdhury H, Moria H (2012) Aerodynamic drag measurement of American footballs. Proc Eng 34:98-103

14. Asai T, Seo K, Kobayashi O, Sakashita R (2007) Fundamental aerodynamics of the soccer ball. Sports Eng 10(2):101-109

15. Bearman PW, Harvey JK (1976) Golf ball aerodynamics. Aeronaut Quart 27(2):112-122

16. Djamovski V, Rosette P, Chowdhury H, Alam F, Steiner T (2012) A comparative study of rugby ball aerodynamics. Proc Eng 34:74-79 